\title{
DOI: http://dx.doi.org/10.33846/sf11110
}

Penetapan Total Flavonoid, Aktivitas Antioksidan dan Karakterisasi Nanopartikel Ekstrak Etanol Daun Kelor (Moringa pterygosperma Gaertn.)

Tinta Julianawati

Ilmu Kesehatan Reproduksi, Fakultas Kedokteran, Universitas Airlangga; tinta.juliana@yahoo.com

(koresponden)

Hendy Hendarto

Departemen Obstetri dan Ginekologi, Fakultas Kedokteran, Universitas Airlangga / RSUD Dr.Soetomo

Surabaya; hndhendy@yahoo.com

Widjiati

Departemen Anatomi Veteriner, Fakultas Kedokteran Hewan, Universitas Airlangga; widjiati1962@gmail.com

\section{ABSTRACT}

Moringa pterygosperma is one of the plants in Indonesia that is often used in herbal medicine. Moringa leaves contain many phytochemical compounds, one of the compounds is flavonoids which function as antioxidants. Flavonoid compounds in vitro can inhibit lipid peroxidation by breaking the chain of peroxyl radicals. Moringa leaf benefits in the field of herbal medicine are formed with a variety of preparations. One of the preparations is in the form of extracts with the aim of attracting chemical components to natural materials The extraction process has a disadvantage because the level of solubility in water is still low. The nanoparticle technique is a strategy to increase the bioavalbicibility of herbal active compounds. This research was experimental in order to determine the total flavonoid levels contained in Moringa leaf extract. In addition, it was also to find out the antioxidant activity and particle size of the moringa leaf extract nanoparticles. Determination of flavonoid levels using spectrophotometric methods. The antioxidant activity of moringa leaf extract nanoparticles was tested using the DPPH method (2,2-diphenyl-picrylhdrazyl) and to determine the particle size used by using the Particle Size Analyzer (PSA). The results of the study showed total flavonoid levels in moringa leaf extract $(1.97 \pm 1.07) \%$. Antioxidant activity of $451.8 \mathrm{ppm}$ with a reduction of $2.8 \%$ and particle size in the moringa leaf extract nanoparticles of $\pm 134.78 \mathrm{~nm}$. Moringa leaf extract nanoparticles include low antioxidants.

Keywords: moringa; nanoparticles; antioxidants

\section{ABSTRAK}

Tanaman kelor (Moringa pterygosperma Gaertn.) merupakan salah satu tanaman yang ada di Indonesia yang sering dimanfaatkan dalam pengobatan herbal. Daun kelor mengandung banyak senyawa fitokimia salah satunya adalah senyawa flavonoid yang berfungsi sebagai antioksidan. Senyawa flavonoid secaraa in vitro terbukti dapat menghambat peroksidasi lipid dengan cara memecah rantai peroxyl radical. Pemanfaatan daun kelor dalam bidang pengobatan herbal dibentuk dengan berbagai sediaan. Salah satu sediaannya adalah dalam bentuk ekstrak dengan tujuan menarik komponen bahan kimia pada bahan alam. Proses ekstraksi memiliki kelemahan karena tingkat kelarutan dalam air masih rendah. Teknik nanopartikel merupakan strategi dalam meningkatkan bioavalaibilitas senyawa aktif herbal. Penelitian ini bersifat eksperimental dengan tujuan untuk mengetahui kadar flavonoid total yang terkandung dalam ekstrak daun kelor. Selain itu juga untuk mengetahui aktivitas antioksidan dan ukuran partikel pada sediaan nanopartikel ekstrak daun kelor. Penentuan kadar flavonoid dengan menggunakan metode spektofotometri. Aktivitas antioksidan pada nanopartikel ekstrak daun kelor diuji dengan menggunakan metode DPPH (2,2-diphenyl-picrylhdrazyl) dan untuk menentukan besar ukuran partikel digunakan dengan menggunakan Particle Size Analyzer (PSA). Hasil penelitian yang diperoleh kadar flavonoid total pada ekstrak daun kelor sebesar $(1,97 \pm 1,07) \%$. Aktivitas antioksidan 451,8 ppm dengan peredaman 2,8\% dan ukuran partikel pada nanopartikel elstrak daun kelor sebesar $\pm 134,78 \mathrm{~nm}$. Sehingga ukuran partikel masih dalam rentang ukuran nanopartikel dan merupakan golongan antioksidan lemah.

Kata kunci: moringa; nanopartikel; antioksidan

\section{PENDAHULUAN}

Indonesia dikenal dengan keaneragaman hayati salah satunya adalah tanaman obat yang bermanfaat bagi kesehatan manusia. Salah satu tanaman yang ada adalah tanaman kelor (Moringa pterygosperma Gaertn.). Daun kelor mengandung berbagai zat kimia yang bermanfaat. Fitokimia dalam daun kelor adalah tannin, steroid dan triterpenoid, flavonoid, saponin, antarquinon, dan alkaloid, semua senyawa merupakan antioksidan ${ }^{(16)}$. Daun kelor juga memiliki kandungan fenolik yang terbukti efektif berperan sebagai antioksidan. Efek antioksidan yang dimiliki tanaman kelor memiliki efek yang lebih baik daripada Vitamin E secara in vitro dan menghambat peroksidasi lemak dengan cara memecah rantai peroxyl radical ${ }^{(10)}$.Penggunaan antioksidan alami saat ini dianggap lebih aman karena antioksidan alami diperoleh dari ekstrak tanaman Senyawa aktif herbal dalam bentuk sediaan ekstrak memiliki kelemahan yaitu rendahnya kelarutan dalam air sehingga menurunkan bioavailabilitasnya. Efisiensi dari penggunaan obat dapat selalu terhambat oleh kemampuan obat itu sendiri 
dalam mencapai tempat aksinya. Nanopartikel adalah salah satu strategi untuk meningkatkan bioavailabilitas senyawa aktif herbal. Nanopartikel merupakan partikel koloid padat dengan diameter 1-1000 nm. ${ }^{(3)}$

Nanopartikel merupakan salah satu strategi untuk meningkatkan bioavailabilitas senyawa aktif herbal. Tujuan utama dalam melakukan nanopartikel sebagai sistem penghantar obat adalah untuk mengatur ukuran partikel, sifat-sifat permukaan, dan pelepasan zat aktif pada tempat yang spesifik di dalam tubuh sebagai sasaran pengobatan. Ukuran partikel yang lebih kecil, maka luas permukaan akan meningkat. Permukaan yang lebih besar akan memungkinkan interaksi yang lebih besar sehingga dapat menyebabkan peningkatan kelarutan ${ }^{(13)}$ .Dalam sistem penghantar obat, nanopartikel berperan sebagai pembawa dengan cara melarutkan, menjebak, mengenkapulasi obat di dalam matriksnya atau pembawanya.

Beberapa penelitian yang memanfaatkan tanaman sebagai antioksidan dengan nanopartikel diantaranya Zulfa (2014) dengan membuat nanopartikel kitosan ekstrak etanol rosela didapatkan hasil bahwa dengan nanopartikel dapat meningkatkan aktivitas enzim SOD. Selain itu pada penelitian yang dilakukan oleh Patabang (2019) didapatkan hasil bahwa daun kluwak dapat digunakan sebagai bioreduktor dalam sintesis nanopartikel perak.

Dalam penelitian ini pembuatan nanopartikel estrak daun kelor menggunakan bahan kitosan. Kitosan merupakan polisakarida alam glukosamin (2-asetamido-2-deoksi-d-glukoosa) $\mathrm{N}$-asetil glukosamin saat ini mulai banyak dimanfaatkan dalam bidang farmasi, kesehatan dan pangan. Kitosan bersifat anti mikroba,tidak beracun, wound healing, biokompatibel, biodegredabel, serta larut dalam air. Kitosan dalam bentuk nanopartikel memiliki keunggulan diantaranya tidak toksik, stabil selama penggunaan, luas permukaan yang tinggi, dapat diaplikasikan untuk berbagai jenis oba dan ekstrak tanaman. Selain itu kitosan dapat digunakan sebagai bahan eksipien atau pembawa sekaligus bahan aktif dalam suatu sediaan topikal. ${ }^{(4)}$

Tujuan dari penelitian ini untuk mengukur kadar flavonoid total yang ada didalam ekstrak daun kelor. Selain itu untuk mengetahui ukuran partikel dalam proses nanopartikel ekstrak daun kelor serta aktivitas antioksidan didalamnya.

\section{METODE}

Bahan tanaman yang digunakan pada penelitian ini adalah daun kelor yang dipanen dari Desa Lodoyo, Kabupaten Blitar, Jawa Timur dan sudah melewati uji determinasi tumbuhan Lembaga Ilmu Pengetahuan Indonesia (LIPI) Purwodadi-Pasuruan Bahan-bahan yang digunakan untuk proses ekstraksi, uji flavonoid total, nanopartikel, dan aktivitas antioksidan adalah etanol 70\% (PT. Brataco Chemika Tbk.) Bahan kimia dan pereaksi yang digunakan hexamethylenetetramine (E.merck), aseton (E.merck) dan HCL 25\% (E.merck), DMSO (PT.Dwi Tunggal Mulia Kimia), Kitosan-NaTPP (PT. Brataco Chemika Tbk.), air, alumunium klorida p.a(E.merck). Alat yang digunakan dalam penelitian ini adalah timbangan kilogram (Five goats), botol gelap, timbangan elektrik (Ohaus), blender (Maspion), vaccum rotary evaporator (Heidolph), dan corong buchner. Alat yang digunakan untuk uji kelarutan batu ginjal adalah mortir, ayakan $40 \mathrm{Mesh}$, alat-alat gelas, spektrofotometer (Perkin Elmer), magnetic strirer (IKA).

Bahan yang digunakan adalah seluruh daun baik daun yang muda maupun yang tua sebanyak 2 kilogram. Daun kelor dicuci hingga bersih kemudian ditiriskan. Selanjutnya untuk proses pengeringan sampel dengan cara daun kelor diangin-anginkan pada suhu ruang. Waktu pengeringan pada suhu ruang kurang lebih 3 hari. Setelah sampel daun kelor kering, dilakukan penghancuran menggunakan blender kering dan di ayak menggunakan ayakan 40 Mesh untuk mendapatkan bubuk sampel.

Serbuk daun kelor sebanya 350 gram ditimbang kemudian ditambahkan pelarut etanol 70\% 1:2 hingga terendam lalu diamkan selama 24 jam dalam bejana maserasi. Rendaman serbuk daun kelor yang telah di rendam 24 jam kemudian di saring hingga didapatkan dengan filtrat hari pertama. Ampas serbuk daun kelor ditambahkan lagi dengan pelarut etanol 70\% 1:2 lalu didiamkan lagi selama 24 jam. Ulangi prosedur peyaringan ekstrak hingga mendapatkan filtrat selama 3 hari kemudian filtrat seluruhnya di pekatkan dengan menggunakan rottary evaporator pada suhu $50^{\circ} \mathrm{C}$ sehingga diperoleh ekstrak kental daun kelor. (Unit Layanan Pengujian,Farmasi UNAIR).

Penentuan kadar flavonoid total adalah:

1. Preparasi sampel: Timbang seksama $1 \mathrm{~g}$ bahan baku, masukkan kedalam labu alas bulat. Kemudian tambahkan $1,0 \mathrm{~mL}$ larutan $0,5 \%(\mathrm{~b} / \mathrm{v})$ hexamethylenetetramine, $20 \mathrm{~mL}$ aseton dan 2,0 $\mathrm{mL}$ HCL $25 \%(\mathrm{~b} / \mathrm{v})$ refluks selama 2 jam sejak mendidih. Saring campuran menggunakan kapas ke dalam labu ukur $100 \mathrm{~mL}$. Bilas kapas dengan aseton, tambahkan aseton sampai $100 \mathrm{~mL}$, kocok homogen. Masukkan 20,0 mL filtrat ke dalam corong pisah, tambahkan $20 \mathrm{~mL}$ air kemudian tambahkan $15 \mathrm{~mL}$ etil asetat, kocok selama 10 menit, biarkan memisah ambil fase etil asetat. Lanjukan ekstraksi 3x masing-masing dengan $10 \mathrm{~mL}$ etil asetat. Gabung fase etil asetat, cuci $2 \mathrm{x}$ masing-masing dengan $50 \mathrm{~mL}$ air. Masukkan hasil ekstraksi ke dalam labu ukur $50 \mathrm{~mL}$. Kemudian tambahkan etil asetat sampai garis tanda, kocok homogen.

2. Prosedur penetapan kadar: Masukkan 10,0 mL fraksi etil asetatke dalam labu ukur $25 \mathrm{~mL}$. Kemudian tambahkan $1 \mathrm{~mL}$ larutan AlCl3 (2 g dalam $100 \mathrm{~mL}$ asam asetat glasial metanol (5+950). Tambahkan asamasetat glasial metanol (5+95) sampai tanda batas volume 
3. Larutan blanko: $10 \mathrm{~mL}$ larutan fraksi etil asetat dimasukkan ke dalam labu ukur $25 \mathrm{~mL}$. Tambahkan larutan asam asetat glasial-metanol (5+95) sampai tanda batas volume. Pengukuran dengan cara larutan sampel didiamkan selama 30 menit, scan antara 300-500 nm. Kemudian ukur absorbansi larutan pada gelombang maksimum $( \pm 435 \mathrm{~nm}){ }^{(1)}$

Perhitungan: \% Flavonoid = Absrobansi sampel x 1,25/g sampel

Pembuatan nanopartikel ekstrak daun kelor adalah: Ekstrak kental daun kelor ditimbang seberat 1 gram kemudian dilarutkan dalam $35 \mathrm{ml}$ dan ditambahkan air aquades sebanyak $15 \mathrm{ml}$ dan ditempatkan pada gelas ukur $2000 \mathrm{~mL}$. Asam glasial 1\% dalam kitosan sebanyak $100 \mathrm{ML}$ dan larutan NaTPP sebanyak $350 \mathrm{~mL}$. Perbandingan kitosan dan NaTPP yaitu 8:1. ${ }^{(6)}$ Kemudian dilaukan pengadukan magnetic strirer selama 2 jam. Nanopartikel dianalisa menggunakan uji Particle Size Analyzer (PSA).

Pengujian aktivitas antioksidan secara kuantitatif dilakukan dengan mnggunakan metode DPPH (2,2diphenyl-picrylhdrazyl). Pembuatan larutan DPPH dengan cara menimbang $2 \mathrm{mg}$ DPPH kemudian dilarutkan dengan metanol di dalam labu ukur sampai $100 \mathrm{ml}$, kemudian dikocok hingga homogen sehingga diperoleh konsentrasi sebesar 0,002\%. Larutan DPPH disimpan dalam kertas alumunium. Larutan blanko dibuat dengan cara menambahkan $2 \mathrm{ml}$ metanol dengan $2 \mathrm{ml}$ larutan DPPH 0,002\% ke dalam tabung reaksi, kemudian di vortex sampai homogen dan diinkubasi pada suhu ruang selama 30 menit dalam ruang gelap. Selanjutnya serapan larutan diukur menggunakan spektofotometri UV-Vis Perkin Elmer Lambda 25 hingga diperoleh panjang gelombang maksimum. ${ }^{(8)}$

Sebanyak $2 \mathrm{ml}$ sampel masing-masing dimasukkan ke dalam tabung reaksi, lalu ditambahkan ke dalamnya $2 \mathrm{ml}$ DPPH 0,002\%. Campuran tersebut kemudian di vortex sampai homogen. Selanjutnya diinkubasi pada suhu ruang selama 30 menit dalam ruang gelap. Serapan di ukur pada panjang gelombang $517 \mathrm{~nm}$ pada spektofotometer UV-Vis Perkin Elmer Lambda 25. (Sumarlin et al.,2012) Pengukuran dilakukan pengulangan sebanyak 3 kali. Sebagai standar digunakan asam askorbat dengan perlakuan yang sama dengan sampel uji. Kemudian dihitung \% inhibisinya dan dimasukkan ke dalam persamaan regresi linier hingga didapat $\mathrm{IC}_{50}$ nya. Nilai serapan larutan DPPH sebelum dan sesudah penambahan sampel tersebut dihitung sebagai persen inhibisi (\% inhibisi) dengan rumus sebagai berikut:

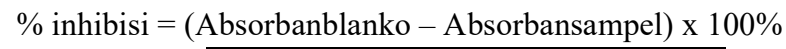

Absorbanblanko

Selanjutnya hasil perhitungan dimasukkan ke dalam persamaan regresi dengan konsentrasi ekstrak (ppm) sebagai abis (sumbu X) dan nilai \% (antioksidan) sebagai kordinatnya (sumbu Y). Nilai $\mathrm{IC}_{50}$ dari perhitungan pada saat $\%$ inhibisi sebesar $50 \% \mathrm{y}=\mathrm{ax}+\mathrm{b}$

\section{HASIL}

\section{Identifikasi Senyawa Flavonoid Ekstrak Daun Kelor}

Prosedur pemeriksaan senyawa flavonoid dengan menggunakan uji flavon total dengan menggunakan spektofotometri. Senyawa ini diidentifikasi sebagai salah satu jenis antioksidan alami yang terdapat pada daun kelor.

Tabel.1 Hasil pengukuran kadar flavonoid

\begin{tabular}{|c|c|c|}
\hline g sampel & Absorbansi & \% Flavonoid \\
\hline 1.0349 & 1.57620 & 1.904 \\
\hline 1.0262 & 1.57970 & 1.924 \\
\hline \multicolumn{2}{|c|}{ Rerata Kadar Flavonoid } & 1.91 \\
\hline RPD & 1.07 \\
\hline
\end{tabular}

Tabel 1. menunjukkan hasil bahwa penetapan kadar flavonoid dari ekstrak etanol daun kelor didapatkan adalah sebesar 1,97 \pm 1,07\%.Nilai absorbansi terbesar pada ekstrak etanol daun kelor adalah 1.57970.

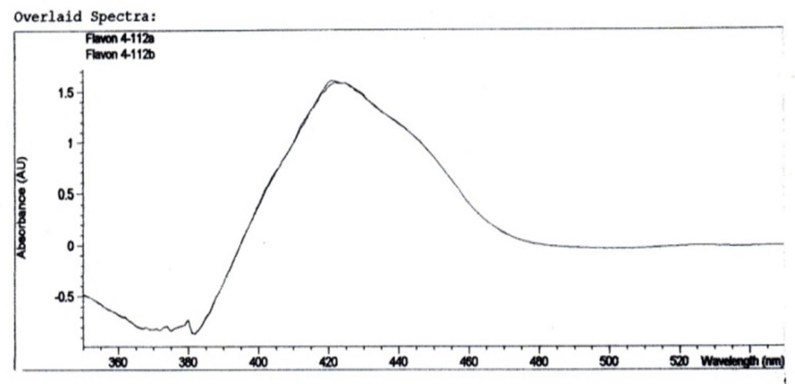

Gambar 1. Hasil sperktrum ekstrak daun kelor 
Pada gambar 1. menunjukkan hasil pengukuran pada spektofotometer UV-Vis dengan semakin besar panjang gelombang menunjukkan nilai absorbansi yang dihasilkan akan semakin rendah. Pengukuran serapan panjang gelombang maksimum dilakukan pada rentang 300-500 nm dan panjang gelombang maksimum yang dihasilkan sebesar $\pm 435 \mathrm{~nm}$.

\section{Ukuran Partikel}

Ukuran partikel merupakan karakteristik nanopartikel yang penting karena menentukan distribusi obat,toksisitas, mempengaruhi drug loading,drug relase, dan kestabilan sistem nanopartikel. Ukuran dan distribusi ukuran partikel nanopartikel dapat diukur menggunakan Alat Particle Size Analyzer (PSA)

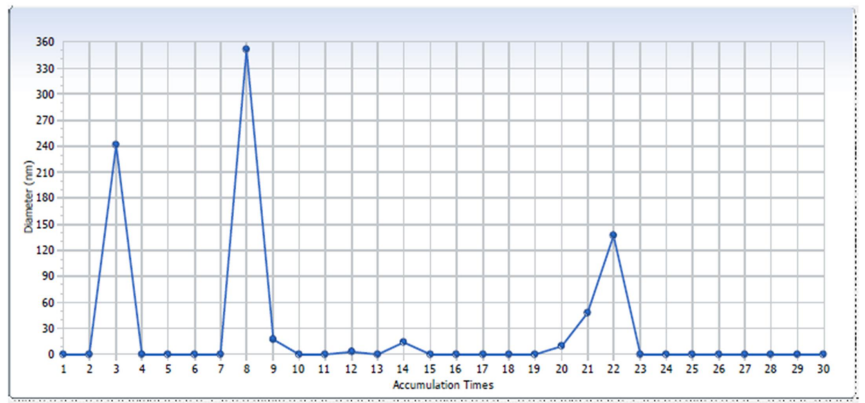

Gambar 2. Hasil uji Particle Size Analyzer (PSA)

Gambar 2. menunjukkan hasil uji nanopartikel ekstrak daun kelor yang diperoleh diukur menggunakan Alat Particle Size Analyzer (PSA) selama pengujian dengan akumulasi waktu selama 30 detik sebesar $\pm 134,78$ $\mathrm{nm}$.

\section{Identifikasi Aktivitas Antioksidan}

Uji ini untuk mengetahui aktivitas antioksidan yang terdapat pada ekstrak etanol daun kelor bertujuan untuk mengetahui kemampuan ekstrak etanol daun kelor dalam menangkap senyawa radikal. Parameter yang digunakan untuk mengetahui besarnya senyawa sebagai antioksidan yaitu nilai Ic50.

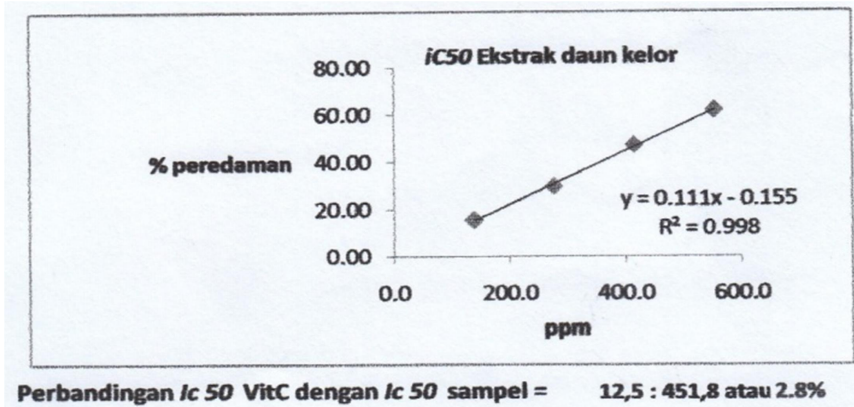

Gambar 3. Perbandingan Ic50 dengan Ic50 sampel

Gambar 3. menunjukkan hasil analisis regresi linier hubungan antara konsentrasi nanopartikel ekstrak daun kelor dengan persen peredaman absorban DPPH diperoleh persamaan regresi $y=0,11 x-0,155$. Pada penelitian ini uji DPPH pada ekstrak etanol daun kelor diabandingkan dengan vit $\mathrm{C}$, hasil yang didapatkan bahwa perbandingan Ic50 VitC dengan Ic50 sampel = 12,5: 451,8 atau (2,8\%) sehingga dapat diartikan bahwa aktivitas antioksidan pada ekstrak etanol daun kelor masih rendah dibandingkan dengan aktivitas antioksidan pada vitC. Pada nanopartikel ekstrak daun kelor hanya mampu meredam 2,8\% dari radikal bebas sebanyak 50\%.

\section{PEMBAHASAN}

Hasil penelitian menunjukkan penetapan kadar flavonoid pada ekstrak etanol daun kelor kelor cukup tinggi. Penetapan ini dengan menggunakan metode alumunium klorida sehingga terjadi pembentukan kompleks antara alumunium klorida dengan gugus keto pada atom C-4 dan gugus hidroksi pada atom C-3 atau C-5 yang berdekatan dari golongan flavon atau flavonol. Pada penelitian ini senyawa yang digunakan sebagai standar penetapan kadar flavonoid adalah quersetin, karena quersetin merupakan golongan flavonol yang memiliki gugus keto pada atom C-4 dan juga gugus hidroksil pada atom C-3 dan C-5 yang bertetangga. ${ }^{(2)}$ 
Penelitian nanopartikel ekstrak daun kelor ini menggunakan bahan kitosan, karena kitosan merupakan bahan yang bersifat bioaktif, biokompatibel, pengkelat, antibakteri dan dapat terbiodegredasi. Nanopartikel dengan bahan kitosan dapat dimanfaatkan dalam penghantar obat dengan target usus besar, penghantar obat pada selaput mukosa, terapi kanker, penghantar gen, penghantar topikal, penghantaran okular dan penghantaran lambung atau salutan pencernaan ${ }^{(7)}$.Kitosan digunakan sebagai penyalut obat selain itu juga digunakan untuk menahan pelepasan obat di dalam tubuh. Pada penelitian ini menggunakan metode gelasi ionik. Metode gelasi ionik merupakan metode yang mudah dibandingkan dengan metode yang lainnya. ${ }^{(12)}$

Mekanisme terbentuknya nanopartikel dengan bahan kitosan dengan cara adanya interaksi elektostatic antara gugus amina dan gugus negatif dari polianion seperti tripolifosfat. Pengadukan kitosan yang larut dalam asam asetat dan penambahan anionik polimer dengan macnetic strirrer bertujuan untuk memecah partikelpartikel agar mendapatkan ukuran nano. Pada ukuran partikel nanopartikel ekstrak daun kelor didapatkan ukuran yang baik dalam sistem penghantar obat karena ukuran tersebut $<300 \mathrm{~nm}$. ${ }^{(5)}$ Bentuk ukuran partikel banyak dipengaruhi oleh beberapa faktor diantaranya konsentrasi TPP, konsentrasi larutan kitosan, rasio volume larutan kitosan dan TPP, lama pengadukan, kecepatan pengadukan, dan lamanya waktu penyimpanan. ${ }^{(7)}$

Uji partikel dengan PSA cenderung menghasilkan ukuran lebih besar dibandingkan dengan metode lain. Hal ini terjadi karena adanya agregasi dan swelling dari partikel kitosan. Agregasi dapat terjadi seiring dengan meningkatnya nilai $\mathrm{pH}$ karena gugus positif $\mathrm{NH}^{3+}$ dari kitosan terikat dengan gugus $\mathrm{OH}$ menarik $\mathrm{H}^{+}$berlebih dari $\mathrm{NH}^{3+}$ membentuk $\mathrm{NH}^{2}$. ${ }^{(6)}$ Kehilangan muatan partikel mengakibatkan antar partikel bertumbuhan mengalami agregasi. Sedangkan swelling terjadi akibat adanya penolakan elektrostatis antar gugus ion yang memiliki muatan. Meningkatnya $\mathrm{pH}$ membuat kelarutan kitosan menurun sehingga ukuran partikel meningkat. Swelling menyebabkan ukuran partikel membesar akibat penyerapan air. Oleh karena itu, penambahan NaTPP pada pembuatan nanopartikel ekstrak daun kelor bertujuan untuk meningkatkan biokompabilitas dan menurunkan derajat swelling pada kitosan. ${ }^{(6)}$

Metode DPPH ini dipilih karena merupakan metode yang sederhana, mudah, cepat, dan peka serta hanya memerlukan sedikit sampel untuk pengujian aktivitas antioksidan dari senyawa bahan alam. Prinsip pengukuran aktivitas antioksidan secara kuantitatif menggunakan metode DPPH ini adalah adanya perubahan intensitas warna ungu DPPH yang sebanding dengan konsentrasi larutan DPPH tersebut. Radikal bebas DPPH yang memiliki elektron tidak berpasangan akan memberikan warna ungu. Warna akan berubah menjadi kuning saat elektronnya berpasangan. Perubahan intensitas warna ungu ini akan terjadi karena adanya peredaman radikal bebas yang dihasilkan oleh bereaksinya molekul DPPH dengan atom hidrogen yang dilepaskan oleh molekul senyawa sampel sehingga terbentuk senyawa 2,2-diphenyl-1-picrylhdrazine dan menyebabkan terjadinya peluruhan warna DPPH dari ungu ke kuning. Perubahan warna ini akan memberikan perubahan absorbansi pada panjnag gelombang maksimum DPPH saat diukur menggunakan spetofotometri UV-Vis sehingga akan diketahui nilai aktivitas peredaman radikal bebas yang dinyatakan dengan nilai Ic50. ${ }^{(12)}$ Hasil aktivitas antioksidan pada nanopartikel ekstrak daun kelor menunjukkan bahwa masih dalam golongan lemah, hal ini diduga karena tidak mengambil senyawa murni atau isolat. Pada penelitian yang dilakukan oleh Ningrum et al (2017) uji aktivitas antioksidan pada teknik isolasi flavonoid menunjukkan bahwa memiliki aktivitas antioksidan yang lebih rendah dari kuersetin sebesar $139,8373 \mathrm{mg} / \mathrm{L}$. Kadar aktivitas antioksidan pada isolat lebih tinggi karena dengan proses isolasi mengambil senyawa murni yang mempunyai kemampuan lebih besar untuk mendonorkan protonnya.

Beberapa penelitian pembuatan material nano juga dilakukan oleh Prasetiowati (2018) dengan melakukan sintesis nanopartikel perak dengan bioreduktor ekstrak daun belimbing wuluh sebagai antibakteri didapatkan hasil bahwa dengan nanopartikel mampu menghambat pertumbuhan bakteri lebih kuat dengan ukuran partikel dengan rata-rata $112,8 \mathrm{~nm}$. Selain itu penelitian juga dilakukan oleh Pakki (2016) membuat formulasi nanopartikel ekstrak daun bawang dayak dengan variasi kitosan - tripolifosfat (TPP) didapatkan hasil bahwa dengan meningkatkan rasio kitosan dan TPP akan menghasilkan nanopartikel yang lebih kecil dengan rasio optimal adalah 5:1. Rasio ini juga menghsilkan efisiensi penyerapan paling baik dan nanopartikel dengan struktur partikel kompak.

\section{KESIMPULAN}

Berdasarkan pembahasan bahwa, hasil aktivitas antioksidan pada nanopartikel ekstrak daun kelor menunjukkan masih dalam antioksidan golongan lemah, hal ini diduga karena tidak mengambil senyawa murni atau isolat. Sehingga disarankan untuk menyempurnakan hasil penelitian ini perlu dilakukan proses isolat agar memperoleh aktivitas antioksidan yang kuat.

\section{DAFTAR PUSTAKA}

1. Aminah, Tomayahu N, Abidin Z. Penetapan Kadar Flavonoid Total Ekstrak Etanol Kulit Buah Alpukat (Persea Americana Mill.) Dengan Metode Spektrofotometri Uv-Vis. Jurnal Fitofarmaka Indonesia. $2013 ; 4(2)$ 
2. Azizah DN, Kumolowati E, Faramayuda F. Penetapan Kadar Flavonoid Metode Alcl3 Pada Ekstrak Metanol Kulit Buah Kakao (Theobroma Cacao L). Kartika Jurnal Ilmiah Farmasi. 2014;2(2):45-49.

3. Azam B, Javanzad S, Saleh T, Hashemi M, Aghasadeghi MR. Nanoparticles Potent Vectors For Vaccine Delivery Targeting Cancer And Infectious Diseases. Human Vaccnes \& Immunoterapeutics. 2014;10(2):321-332.

4. Dail MT, Huang Y. Chitosan Preparations For Wounds And Burns: Antimicrobial And Wound-Healing Effects . Expert Rev Anti Infect Ther. 2011;9(7): 857-879

5. Gupta S, Lucky Sekhon,Yesul K, Ashok. The Role Of Oxidative Stress And Antioxidants In Assisted Reproduction. Current Women`S Health Reviews. 2010;(6):227-238.

6. Husniati, Oktarina E. Sintesis Nano Partikel Kitosan Dan Pengaruhnya Terhadap Inhibisi Bakteri Pembusuk Jus Nenas. Jurnal Dinamika Penelitian Industri. 2014;25(2).

7. Jianghua L, Cai C, Li J, Yu G. Chitosan-Based Nanomaterials For Drug Delivery. J.Molecules. 2018;23(10):2661.

8. Hasanah M, Maharani B, Munarsih E. Daya Antioksidan Ekstrak Dan Fraksi Daun Kopi Robusta (Coffea Robusta) Terhadap Pereaksi Dpph (2,2-Difenil-1-Pikrilhidrazil). Indonesian Journal Of Pharmaceutical Science And Technology. 2017; 4:(2)

9. Ermina P, Sumarheni, Aisyah F, Ismail, Safirahidzni S. Formulasi Nanopartikel Ekstrak Bawang Dayak (Eleutherine Americana (Aubl) Merr) Dengan Variasi Konsentrasi Kitosantripolifosfat (TPP). J. Trop. Pharm. Chem. 2016;3(4)

10. Reddy PV, Mahalingu S, Urooj A. Abrus Precatorius Leaves: Antioxidant Activity In Food And Biological Systems, pH, And Temperature Stability. International Journal Of Medicinal Chemistry. 2014.

11. Prasetiowati ATP, Wardani S. Sintesis Nanopartikel Perak Dengan Bioreduktor Ekstrak Daun Belimbing Wuluh (Averrhoa Bilimbi L.) Sebagai Antibakteri.Indo. J. Chem. Sci. 2018;7(2).

12. Patabang, Kasim S, Taba P. Sintesis Nanopartikel Perak Menggunakan Ekstrak Daun Kluwak Pangium edule Reinw Sebagai Bioreduktor dan Uji Aktivitasnya Sebagai Antioksidan. Jurnal Ilmu Alam dan Lingkungan.2019;10(1):42-50.

13. Rizkayanti, Anang Wahid, Diah M, Minarni RJ. Uji Aktivitas Antioksidan Ekstrak Air Dan Ekstrak Etanol Daun Kelor (Moringa Oleifera Lam) Antioxidant Activity Tests Of Water And Ethanol Extracts Of Moringa (Moringa Oleifera Lam) Leaves. J. Akad. Kim. 2017;6(2): 125-131.

14. Rizvi Syed AA, Ayman M. Saleh. Applications Of Nanoparticle Systems In Drug Delivery Technology.Elsevier. 2018;26(1):64-70.

15. Sumarlin LO, Suprayogi A, Rahminiwati M, Tjahja A. Bioaktivitas Ekstrak Metanol Daun Namnam Serta Kombinasinya Dengan Madu Trigona. J.Teknologi Dan Industri Pangan. 26(2):144-154.

16. Ulayya Hanidya Fidela, Yuniar Ayu Limantini Suwele, Erika Indah Junior, dan Nisia Anindita Rinjani. Pemanfaatan Lendir Bekicot Afrika (Achatina Fulica) Sebagai Obat Luka Bakar Berbasis Nanoemulsi. Jurnal Ilmiah Farmasi. 2018;6(2):91-94.

17. Vergara M, Almatrafi MM, Fernandez ML. Bioactive Components In Moringa Oleifera Leaves Protect Against Chronic Disease. J.Antioxidant. 2017;6(4):91.

18. Zulfa, Nurkhasanah, Laela Hayu. Aktivitas Antioksidan Sediaan Nanopartikel Kitosan Ekstrak Etanol Rosela (Hibiscus Sabdariffa L.) Pada Tikus Hiperkolesterol Terhadap Aktivitas Enzim SOD. Kartika Jurnal Ilmiah Farmasi. 2014;2(1):7-14. 